\title{
Amylase in the Saliva and in the Gastric Aspirates of Premature Infants: Its Potential Role in Glucose Polymer Hydrolysis
}

\author{
CHARLES HODGE ${ }^{(30)}$ EMANUEL LEBENTHAL ${ }^{(29)}$ P. C. LEE, AND WILLIAM TOPPER \\ Department of Pediatrics, State University of New York at Buffalo, Division of Gastroenterology and Nutrition, \\ Children's Hospital of Buffalo, Buffalo, New York, USA
}

\begin{abstract}
Summary
Amylase activity was found in saliva from 13 infants, $26-42$ wk corrected gestational age. The levels of salivary amylase activity increased with advancing age. In 10 infants, 31-38 wk corrected gestational age (estimated gestational age in wk plus age in wk after birth), gastric aspirates collected before a feeding and sequentially at 30-min intervals after two consecutive feedings were analyzed for amylase activity and $\mathrm{pH}$. Two different postprandial patterns were obtained. For six of the 10 infants, both the pH and amylase activities of their gastric aspirates showed a distinct maxima at about $60 \mathrm{~min}$ after a feeding and a minima at 180 min just before the second feeding. In the remaining four infants, the $\mathrm{pHs}$ of their gastric aspirates remained relatively high (5.0-6.0) for the entire postprandial period. In these infants, there was a persistently high level of the amylase activity. In all 10 infants, amylase activity was found in their gastric aspirate samples when the $\mathrm{pH}$ was above 3.0. Comparison of the amylase in the gastric aspirate with purified pancreatic and salivary amylases by polyacrylamide gel electrophoresis showed that the amylase in the gastric aspirate has an electrophoretic mobility similar to that of salivary amylase, which suggests a salivary origin. This study supports the possibility that salivary amylase could enter the stomach and retain a significant amount of its activity in premature infants.
\end{abstract}

Starch and glucose polymers are given in some formulas to infants very early in life to accommodate the increased caloric demands. Clinical intolerance to glucose polymers has not been examined sufficiently. Pancreatic amylase is the key enzyme in hydrolysis of glucose polymers. Recognition of intolerance to glucose polymers has been rare in spite of the lack of pancreatic amylase in the duodenal fluids of young infants. In part, this can be due to the existence of alternate pathways with auxiliary enzymes for the hydrolysis of glucose polymers during the physiologic deficiency of pancreatic amylase. The auxiliary enzymes include: salivary amylase, small intestinal brush border glucoamylase and mammary amylase in the breast-fed infant. We have shown that glucoamylase reaches levels similar to those of older children at 1 month of age (13). Two studies have noted the presence of $\alpha$-amylase in preterm and in term human milk. The ability of milk amylase to survive the gastric environment has been examined and its physiologic importance in the young infant discussed $(11,16)$. Recently, we also reported an investigation on the possible role of ingested mammary amylase in the hydrolysis of glucose polymers (10). Salivary amylase has been shown to be present in infancy and to reach adult levels much earlier than pancreatic amylase $(1,4,5,15,21,28)$. The level of salivary amylase in premature infants is however not known. In this study we determined whether the salivary amylase was present and active in gastric fluids during feeding.

\section{MATERIALS AND METHODS}

Subjects. The group of prematures included in this study was recruited from the neonatal intensive care unit at the Children's Hospital of Buffalo. They were fed either Similac PM 60/40 or Enfamil Premature Formula, neither of which contained detectable amylase activity. Their ages ranged from $26-42 \mathrm{wk}$ corrected gestational age (estimated gestational age in wk plus age in wk after birth). Samples of saliva and gastric fluid were obtained for assay after written informed consent was obtained from the infants' parents. All procedures used were approved by the Institutional Committee for Human Research at the Children's Hospital of Buffalo.

Sample collection. Samples of saliva were obtained from all 13 infants over a 5 -min period by intermittent aspiration with a suction catheter. The samples were collected over ice, frozen immediately, and then stored at $-20^{\circ} \mathrm{C}$. The amylase activity was determined for aliquots of undiluted saliva within $24 \mathrm{~h}$ after collection. In 10 premature infants, $1-\mathrm{ml}$ aspirates of gastric fluid were obtained before each feeding and at 30-min intervals after each feeding for two consecutive feedings between 9:00 a.m. and 4:00 p.m. All infants were bolus fed through a nasogastric tube, which was allowed to remain in position after each feeding. The nasogastric tube was cleared with air before each sampling. Samples were collected over ice and remained in ice for not more than $2 \mathrm{~h}$. For each sample, the $\mathrm{pH}$ was determined immediately after collection. Then the sample was frozen and stored at $-20^{\circ} \mathrm{C}$. The amylase activity was determined within $24 \mathrm{~h}$ after collection. Each sample was thawed while being centrifuged in a microfuge (Beckman) at room temperature for $2 \mathrm{~min}$. The supernatant was removed by pipette and mixed while being pipetted into another microtube. An aliquot from the second microtube was assayed for amylase activity and the remainder of the sample was frozen for further analysis. The centrifugation step was necessary because of the high background interference in the amylase assay for samples which were not centrifuged.

Amylase assay. Amylase activity was determined by using the Phadebas (Pharmacia, Uppsala, Sweden) insoluble starch method. Phadebas tablets were suspended in a phosphate buffer (20 mM), pH 7.0 to which $5 \mathrm{mg} / \mathrm{ml}$ bovine serum albumin, fraction V (Miles Laboratories, Elkhardt, IN) had been added. This has been shown to give results comparable to those of the saccharogenic method (19) using dinitrosalicylic acid as the chromophore and soluble starch as the substrate. A standard curve was constructed using dilutions of a human serum amylase standard of known concentration of activity for the Phadebas assay. 
Electrophoresis. Aliquots of saliva and gastric fluid were analyzed by slab gel electrophoresis $(7.5 \%$ polyacrylamide, LKBProdukter $\mathrm{AB}$, Bromma, Sweden) in a Tris $\mathrm{HCl}$ buffer at $\mathrm{pH}$ 8.9. Tris-glycine ( $\mathrm{pH} \mathrm{8.9)}$ was used as the running buffer. The samples were used without any prior treatment. Plates were run for $6 \mathrm{~h}$ at a constant current of $40 \mathrm{~mA}$ at $4^{\circ} \mathrm{C}$. Amylase activity was visualized by incubation in a $4 \%$ soluble starch solution for $30 \mathrm{~min}$ at $37^{\circ} \mathrm{C}$ and then stained with iodine. The location of the amylase appeared as a yellow band on a dark blue background. Purified human salivary amylase, purified homogenized pancreatic amylase and samples of premature formulas were run on the same plate as controls.

Purification of amylase. Purified salivary and pancreatic amylases were isolated from human saliva and autopsied pancreas by the affinity gel method with sepharose $6 \mathrm{~B}$ and cyclodextrin as the ligand as described previously (10).

\section{RESULTS}

Figure 1 shows the range of amylase activity in the saliva from various infants at different gestational ages. All salivary samples studied contained amylase activity. There is overlap of the levels of activity in different age groups. The pattern however shows a definite trend of increasing activity with increasing age.

Table 1 lists the maximal amylase activities found in the 10 premature infants from whom gastric aspirates were obtained in relation to two consecutive feedings. Analyses of the results from all samples of gastric fluids from the 10 premature infants revealed two subgroups (I and II), with each subgroup showing a characteristic change in the pattern of gastric $\mathrm{pH}$ and amylase activity. Subgroup I consisted of six infants and subgroup II four infants. These results are presented separately in Figures 2 and 3.

Figure 2 shows the characteristic pattern of infants in subgroup I. Their gastric $\mathrm{pH}$ rose from a baseline level of 2.0 to 3.5 to a peak of 5.5 to 6.5 immediately after a feeding and then showed a gradual decline towards the baseline values. The amylase activity followed the $\mathrm{pH}$ change closely.

Figure 3 shows the characteristic pattern for subgroup II. In this group, no distinct pattern could be discerned. The gastric aspirates maintained a $\mathrm{pH}$ between 5.0-6.5 during most of the period after a feeding. The amylase activities peaked at various times and lacked a consistent pattern.

To see if the amylase in the gastric aspirate was of salivary origin, gastric aspirates were analyzed by polyacrylamide gel electrophoresis. Figure 4 shows a picture of the gel after iodinestarch staining for amylase activity. All except one of the samples of gastric fluid have an amylase with electrophoretic mobility similar to purified salivary amylase, which is distinctly different from pancreatic amylase.

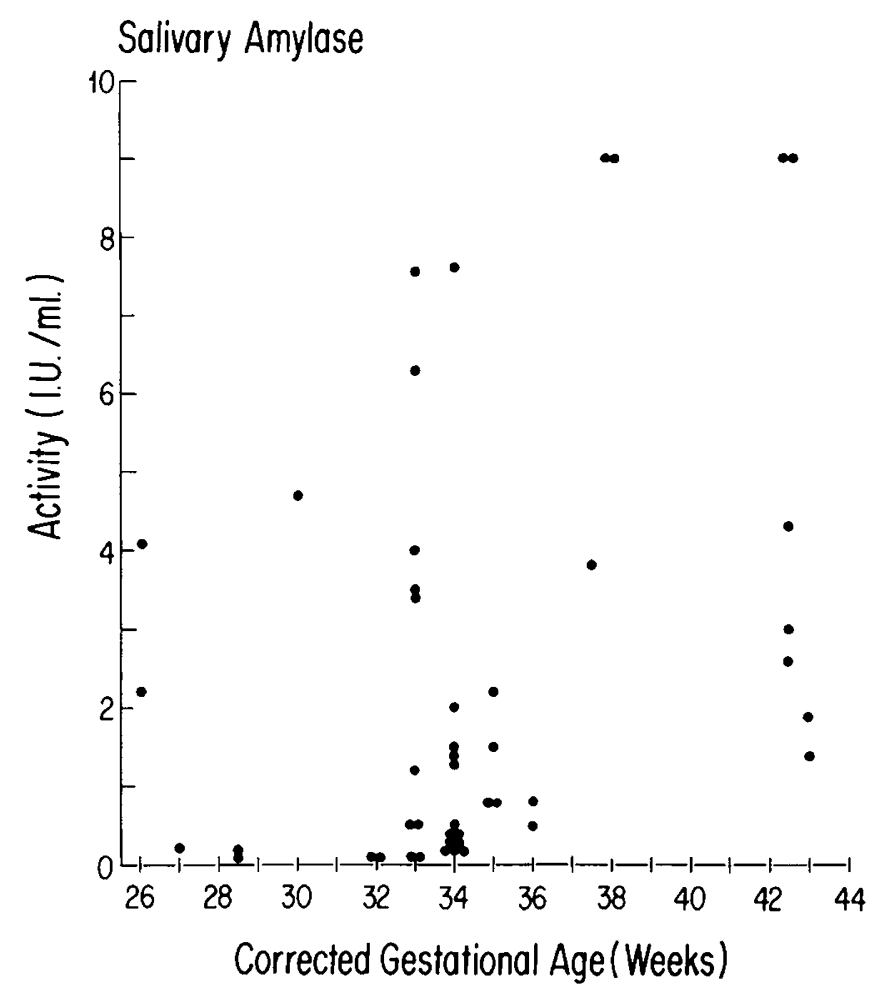

Fig. 1. Amylase activity in aliquots of saliva from 13 infants $26-43$ wk corrected gestational age (estimated gestational age in wk plus age in wk after birth).

\section{DISCUSSION}

Infants younger than 4-6 months of age are known to have low levels of, or a complete absence of, pancreatic amylase (13, 24); however, they seem to tolerate moderate amounts of starch. Recent studies have suggested the presence of alternative enzymes for the digestion of starch and glucose polymers. These include glucoamylase (14), mammary amylase $(10,11,16)$, and salivary amylase (15).

Few reports have investigated the developmental physiology of salivary amylase, particularly in the premature infant. Rossiter et al. (21) and Collares et al. (4) have described a normal pattern of appearance of activity in full term infants and children. There is a gradual increase in the level of activity from birth such that adult levels are attained by about 9-12 months of age. The present study demonstrates that the saliva of premature infants, irrespective of age, had amylase activity. Furthermore, there is a

Table 1. Gastric fluids

\begin{tabular}{|c|c|c|c|c|c|c|}
\hline & \multirow[b]{2}{*}{ Patient } & \multirow{2}{*}{$\begin{array}{l}\mathrm{EGA}^{1} \\
(\mathrm{wk})\end{array}$} & \multirow{2}{*}{$\begin{array}{l}\mathrm{CGA}^{1} \\
(\mathrm{wk})\end{array}$} & \multirow{2}{*}{$\begin{array}{l}\text { Wk } \\
\text { fed }\end{array}$} & \multicolumn{2}{|c|}{$\begin{array}{l}\text { Max. amylase activity } \\
\text { (I.U./ml.) }\end{array}$} \\
\hline & & & & & Feeding 1 & Feeding 2 \\
\hline \multirow[t]{7}{*}{ Group I } & 1 & $24 \frac{1}{2}$ & 33 & 7 & 0.3 & 1.8 \\
\hline & 2 & $26^{1 / 2}$ & $331 / 2$ & 4 & 0.1 & 0.1 \\
\hline & 3 & 28 & $341 / 2$ & 6 & 0.5 & 0.7 \\
\hline & 4 & 34 & 35 & $1 / 2$ & 1.5 & 0.7 \\
\hline & 5 & 35 & 36 & $1 / 2$ & 0.2 & 0.1 \\
\hline & & 35 & $371 / 2$ & $11 / 2$ & 2.0 & 0.9 \\
\hline & 6 & 32 & 38 & $51 / 2$ & 1.0 & 0.4 \\
\hline \multirow[t]{5}{*}{ Group II } & 1 & 29 & 31 & 2 & 0.3 & 0.1 \\
\hline & & 29 & 32 & 3 & 0.5 & 0.2 \\
\hline & 2 & 28 & 34 & $5^{1 / 2}$ & 0.5 & 0.5 \\
\hline & 3 & 30 & $341 / 2$ & 3 & 0.3 & 0.3 \\
\hline & 4 & 35 & 36 & $1 / 2$ & 0.1 & 0.5 \\
\hline
\end{tabular}

${ }^{1} \mathrm{CGA}($ corrected gestational age $)=\mathrm{EGA}($ estimated gestational age $)+$ age after birth. 


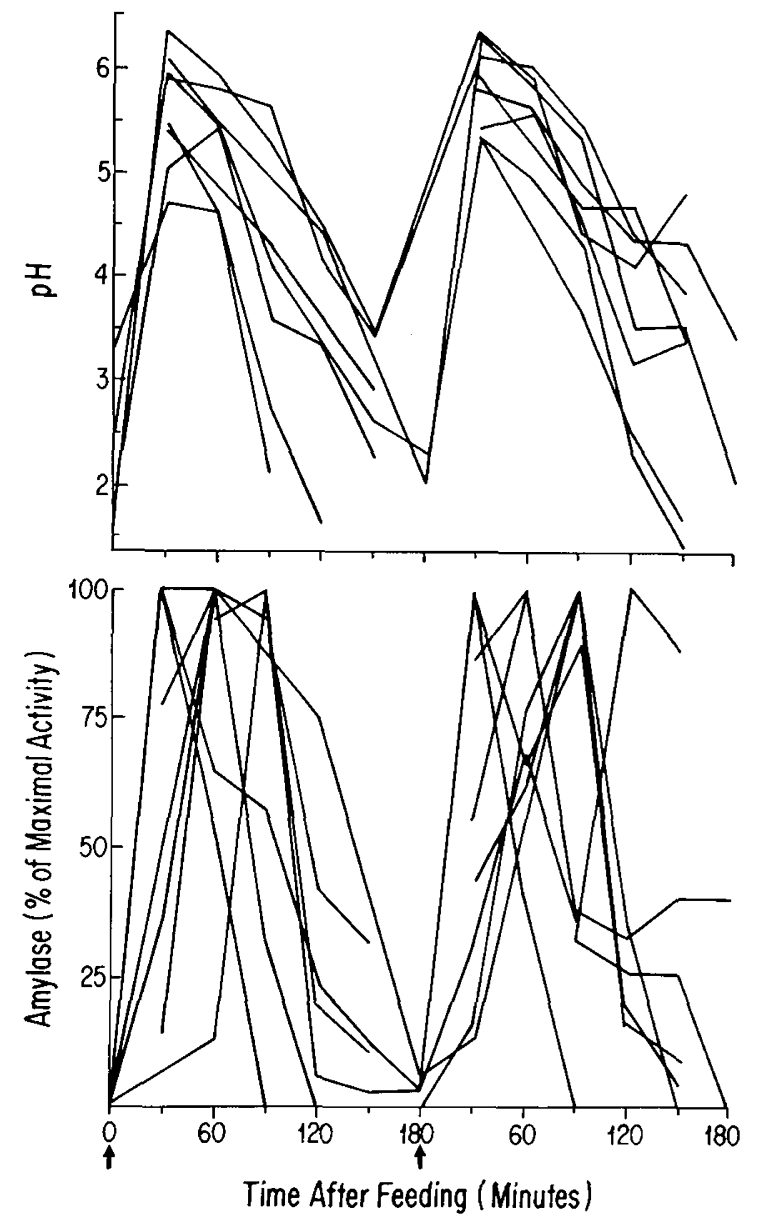

Fig. 2. Patterns of $\mathrm{pH}$ and amylase activity for six premature infants in subgroup I. Arrows on the x axis indicate time of feeding. Amylase activity for each time after a feeding has been normalized against the maximal activity for that feeding interval for better comparison between different infants. They were expressed as the \% of maximal activity for that feeding interval. Values for maximal activities were listed in Table 1 .

trend suggestive of an increase of amylase activity with an increase in age. These findings are similar to those derived from amniotic fluid studies from which similar levels of salivary amylase activity have been calculated from $16 \mathrm{wk}$ of gestation to term (20).

The role of salivary amylase in the digestion of starch and glucose polymers has been a subject of controversy $(12,15)$. There have been reports demonstrating the presence of salivary amylase in duodenal fluid by duodenal intubation $(26,27)$. Our own study of duodenal fluids, collected from infants less than 1 year of age, also showed similar findings. In nine of 10 fluids collected, non-pancreatic amylase, presumably salivary amylase, (identified by its sensitivity to a wheat inhibitor that specifically inhibits the salivary isoamylases) seems to represent the majority of the activity (9). These results suggest the presence of salivary amylase in duodenal fluids in most neonates. There are however questions as to whether the saliva would survive transit through the stomach, because of the tube during intubation, but would not survive if it relied on gastric emptying, because it would be destroyed as a result of longer exposure to acid in the gastric environment. In vitro studies have shown that salivary amylase retains its activity in a $\mathrm{pH}$ range of 4.0-9.0 $(2,18)$. In neonates, Christie (3) and others $(6,17)$ have noted that although the basal gastric $\mathrm{pH}$ is low $24-48 \mathrm{~h}$ after birth, it then increases to between $3.0-4.0$ and does not decrease to adult levels until 3-4 months of age. The gastric $\mathrm{pHs}$ in prematures, both basal and postprandial, have not been documented. In view of the less mature gastric mucosa, prematures may even have a lower capacity to secrete enough acid to overcome the buffering effect of the diet (3). The end result would be a milder gastric environment with a higher $\mathrm{pH}$. In these infants, the amylase in saliva would stand a better chance of surviving the transit through the stomach.

The results from the present study demonstrate that this is indeed the case in premature infants. Their gastric $\mathrm{pH}$ remains relatively high (between 4.0-6.0) and amylase activities were found in all the gastric aspirates whose $\mathrm{pH}$ was above 3.0. Of particular interest is the fluctuation of amylase activity which seems to be correlated with the $\mathrm{pH}$ after a feeding. In six of the 10 infants, the maximal activity occurred within the first $90-120$ min after a feeding. This has been estimated to be the time required for the stomach to empty most of its contents (25). During this interval, the $\mathrm{pH}$ was above 4.0 , which protects much of the amylase activity. Although the formulas have a $\mathrm{pH}$ of 6.0 7.0 , the $\mathrm{pH}$ profile observed is probably related to both the buffering effect of the formula and the inability of the parietal cells to secrete acid. This high $\mathrm{pH}$ environment not only protects the amylase, but also may permit the amylase to begin hydrolysis of a suitable substrate. In the four infants in group II who did not show a distinct postprandial pattern, the gastric pH was even higher (between 5.0-6.0) throughout most of the feeding interval. The exact reason for this is not known but it may reflect a slower emptying of contents or a lesser capacity to secrete acid. The amylase activity levels though erratic were present in most instances.

More importantly, we showed that the amylase found in the gastric aspirates resembles salivary amylase and thus most likely came from the saliva of the infants. These results indicate that
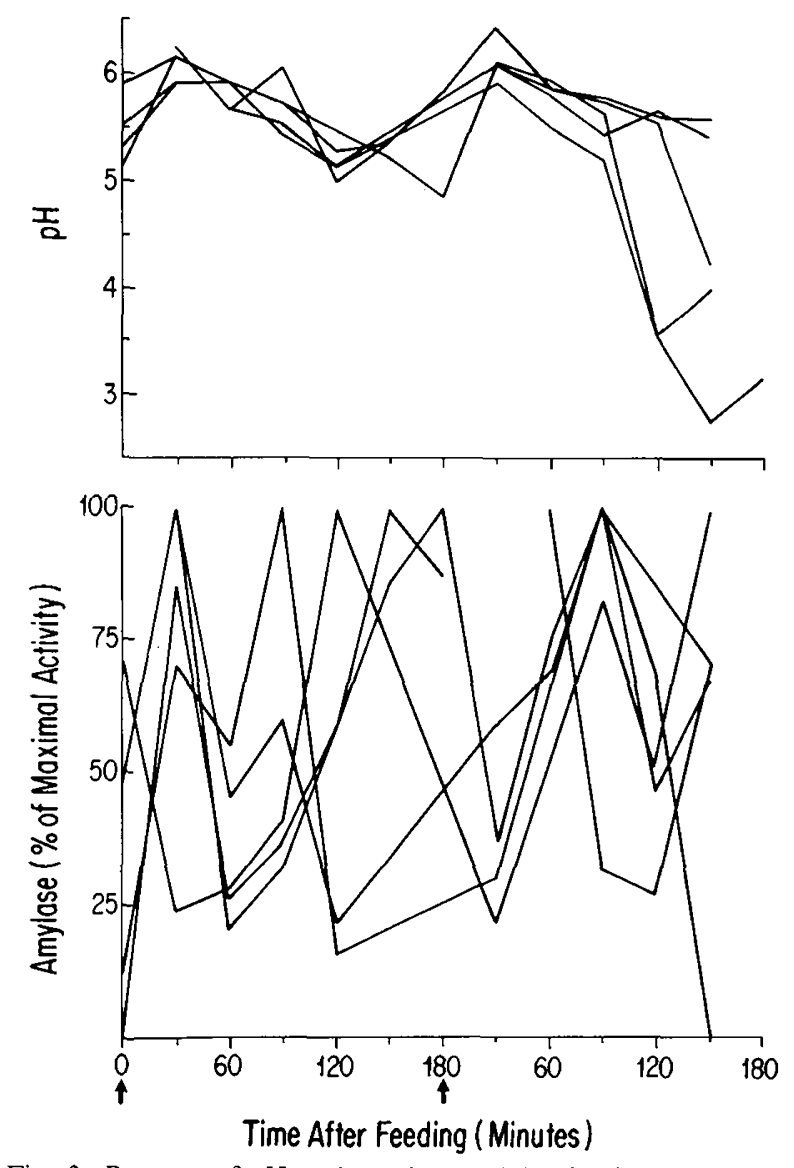

Fig. 3. Patterns of $\mathrm{pH}$ and amylase activity for four infants in subgroup II. Arrows at 0 and $180 \mathrm{~min}$ indicate the time of feedings. Amylase activity for each time after a feeding has been normalized against the maximal activity for that feeding interval for better comparison between different infants. They were expressed as the \% of maximal activity for that feeding interval. Values for maximal activities were listed in Table 1 . 


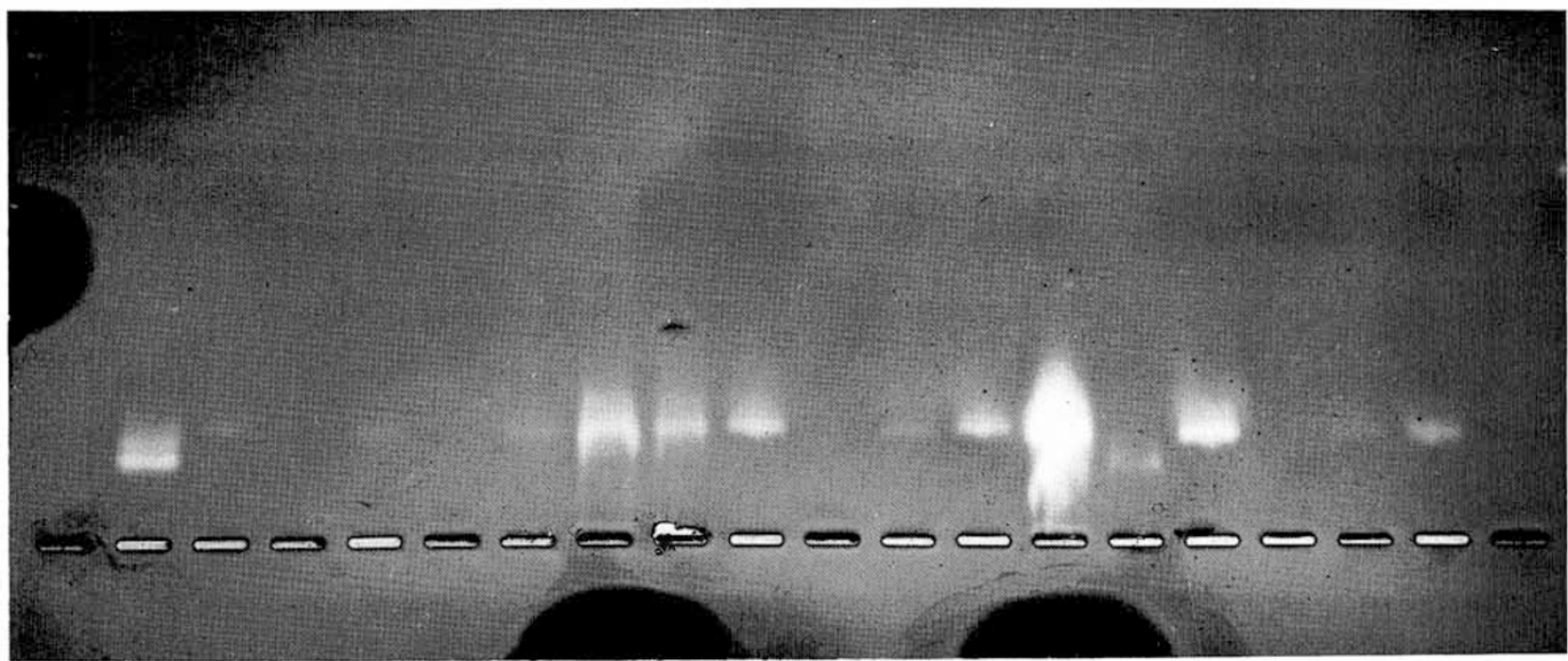
1
23
4
567
8
910
$11 \quad 12$
1213
$3 \quad 14 \quad 1516$
$17 \quad 18$
$19 \quad 20$

Fig. 4. Photograph of polyacrylamide slab gel after electrophoresis, incubation in starch solution and staining with iodine for amylase activity. Well 1, Similac PM 60/40; Well 2, purified homogenized autopsy pancreas; Wells 4, 7, 9, 12, 15, 16, 18, gastric fluid (31-42 wk CGA); Wells 3, 5 , $6,8,10,11,13,14,17$, saliva (28-42 wk CGA); Well 19, purified salivary amylase; and Well 20, Enfamil premature formula.

salivary amylase remains active in the gastric environment of these infants and should survive passage into the duodenum where conditions are optimal for its activity. In vitro studies (22, 23) have shown significant hydrolysis of glucose polymers with $3 \mathrm{unit} / \mathrm{ml}$ of salivary amylase, which is similar to the maximal level observed in some of the aspirates. Therefore, analagous to the lingual lipase for lipid digestion $(7,8)$, salivary amylase may be important as an alternative pathway for the initial digestion of polymers of glucose in prematures and neonates in whom there is a physiologic deficiency of pancreatic amylase and the gastric acidity has not attained adult levels.

\section{REFERENCES AND NOTES}

1. Berg, N. O., Borulf, S., Jakobsson, I., and Lindberg, T.: How to approach the child suspected of malabsorption. Acta Paediatr. Scand., 67: 403 (1978).

2. Bernfeld, P.: Amylases, $\alpha$ and $\beta$. In: S. P. Colowick and N. O. Kaplan, Eds.. Methods in Enzymology, Volume I, p. 149 (Academic Press, New York. 1955).

3. Christie, D. L.: Development of gastric function during the first month of life. In: E. Lebenthal, Ed., Textbook of Gastroenterology and Nutrition in Infancy, pp. 109-120 (Raven Press, New York, 1981).

4. Collares, E. F., Brasil, M. do R. L., and Kawazaki, S. T.: Secrecao de saliva concentracao e secrecao da amilase salivar humana no primeiro ano de vida. Arq. Gastroenterol., S. Paulo, 16: 91 (1979).

5. Delachaume-Salem, E. and Sarles, H.: Evolution en fonction de l'age de la secretion pancreatique humaine normale. Biol. Gastroenterol. (Paris). 2: 135 (1970).

6. Deren, J. S.: Development of structure and function in the fetal and newborn stomach. Am. J. Clin. Nutr., 24: 144 (1971).

7. Hamosh, M., Scanlon, J. W., Ganot, D., Likel, M., Scanlon, K. B., and Hamosh, P.: Fat digestion in the newborn: characterization of lipase in gastric aspirates of premature and term infants. J. Clin. Invest., 67: 838 (1981).

8. Hamosh, M. and Scow, R. O.: Lingual lipase and its role in the digestion of dietary fat. J. Clin. Invest., 52: 88 (1973).

9. Heitlinger, L. A., Lee, P. C., Brooks, S. P., and Lebenthal, E.: Human amylases: identification of pancreatic, salivary and mammary amylases in duodenal fluids. Gastroenterology (abstract), 82: 1005 (1982).

10. Heitlinger, L. A., Lee, P. D., Dillon, W. P., and Lebenthal, E.: Mammary amylase: a possible alternate pathway of carbohydrate digestion in infancy. Pediatr. Res., 17: 15 (1983).

11. Jones, J. B., Mehta, N. R., and Hamosh, M.: $\alpha$-Amylase in preterm human milk. J. Pediatr. Gastroenterol. Nutr., 1: 43 (1982).

12. Lebenthal, E.: Use of modified food starches in infant nutrition. Am. J. Dis. Child., I32: 850 (1978).
13. Lebenthal, E. and Lee, P. C.: Development of functional response in human exocrine pancreas. Pediatrics, 66: 556 (1980).

14. Lebenthal, E. and Lee, P. C.: Glucoamylase and disaccharidase activities in normal subjects and in patients with mucosal injury of the small intestine. J. Pediatr., 97: 389 (1980).

15. Lee, P. C.: Alternate pathways in starch digestion: their importance in premature and young infants. In: F. Lifshitz. Ed., Carbohydrate Intolerance in Infancy, pp. 223-233 (Marcel Dekker. Inc.. New York, 1982).

16. Lindberg, T. and Skude, G.: Amylase in human milk. Pediatrics, 70: 235 (1982).

17. Mason, S.: Some aspects of gastric function in the newborn. Arch. Dis. Child. 37: 387 (1962).

18. Merritt, D. A. and Karn, R. C.: The human $\alpha$-amylases. Adv. Genet., 8: 135 (1977).

19. O'Donnell, M. D. and McGeeney, K. F.: Comparison of saccharogenic and Phadebas methods for amylase assay in biological fluids. Enzyme, 18: 348 (1974).

20. Ogita, S., Noma, H., Kawamura, T., Shimura, K., Ohnishi, M.. Ishiko, O. and Sugawa, T.: Differentiation of amylase isozyme in amniotic fluid with fetal age. Am. J. Obstet. Gynecol., 131: 63 (1978).

21. Rossiter, M. A., Barrowman, J. A.. Dand, A., and Wharton, B. A.: Amylase content of mixed saliva in children. Acta Paediatr. Scand., 63: 389 (1974).

22. Saito, N., Horiuchi, T., Yoshida. M., and Imai. T.: Action of human pancreatic and salivary $\alpha$-amylases on malto-oligosaccharides: evaluation of kinetic parameters. Clin. Chim. Acta, 97: 253 (1979).

23. Saito, N. and Horiuchi, T.: Action of human alpha amylases on reduced maltooligosaccharides. Carbohydr. Res., 96: 138 (1981).

24. Shwachman, H. and Leubner, H.: Mucoviscidosis. Adv. Pediatr., 7: 249 (1955),

25. Siegel, M., Lebenthal, E., Topper, W., Krantz, B., and Li, P. K.: Gastric emptying in prematures of isocaloric feedings with differing osmolalities. Pediatr. Res., 16: 141 (1982).

26. Skude, G. and Ihse, I.: Salivary amylase in duodenal aspirates. Scand. J. Gastroenterol., 11: 17 (1976).

27. Townes, P. L. and White, M. R.: Identity of two syndromes: proteolytic lipolytic, and amylolytic deficiency of the exocrine pancreas with congenital anomalies. Am. J. Dis. Child., 135: 238 (1981).

28. Zoppi, G., Andreotti, G., Pajno-Ferrara, F., Njai, D. M., and Graburro. D.: Exocrine pancreatic function in premature and full term neonates. Pediatr. Res., 6: 880 (1972).

29. Requests for reprints should be addressed to: Emanuel Lebenthal, M.D. Division of Gastroenterology and Nutrition. Children's Hospital, 219 Bryant Street, Buffalo, New York 14222.

30. The present address of Charles Hodge, M.D.. Section of Gastroenterology. The Children's Mercy Hospital, 24th at Giliham Road, Kansas City, Missouri 64108.

31. This research was supported by NIH grant \#12586 and Mead Johnson and Ross Companies grants-in-aid.

32. Received for publication May 6, 1983.

33. Accepted for publication August 17, 1983. 